\title{
O ESTÁGIO EM FINANÇAS: UMA ANÁLISE COMPARATIVA DA REMUNERAÇÃO DE ESTUDANTES DE GRADUAÇÃO EM ENGENHARIA DE PRODUÇÃO DE 2017 A 2019
}

Eduardo Menezes Duarte (Universidade Federal do Paraná) eduardo.emd27@ gmail.com Maria Eliza Casagrande Lazzaretti (Universidade Federal do Paraná) liza.pugli@gmail.com Raphael dos Reis Tomaz (Universidade Federal do Paraná) raphaelreisr@gmail.com Ruth M. Hofmann (Universidade Federal do Paraná) ruthofmann@ gmail.com Vitória de Melo Schroeder (Universidade Federal do Paraná) vitoria.melos@ outlook.com

\section{Resumo}

Este trabalho apresenta uma análise da remuneração auferida por estudantes de Engenharia de Produção da Universidade Federal do Paraná que realizaram estágio na área financeira de 2017 a 2019. A análise se caracteriza como estudo de caso quantitativo que recorre à estatística descritiva para identificar eventuais fatores que possam estimular ou desestimular os estudantes a atuarem na área financeira. Os dados foram obtidos a partir de 145 contratos de estágio. Para efeito de análise os estágios foram agrupados de acordo com a natureza da atividade realizada no estágio. Os agrupamentos se deram em: setor administrativo, setor financeiro, setor comercial e setor operacional. Dentre os resultados obtidos pode-se mencionar a comparação da remuneração entre os estudantes que atuam na área financeira e as demais: a maior remuneração média foi identificada para o setor financeiro, sendo este também o que apresentou maior desvio-padrão da bolsa-auxílio dos estudantes.

Palavras-Chaves: bolsa-auxílio; estágio curricular; graduação.

\section{Introdução}

As mudanças no mercado de trabalho de Engenheiros têm sido objeto de investigação de Farr e Merino (2003) no contexto das mudanças na própria dinâmica da realidade empresarial. Uma formação caracterizada pela ausência de competências e habilidades valorizadas pela indústria pode acabar por restringir o potencial de atuação de engenheiros especificamente em empresas de natureza industrial (FARR; MERINO, 2003). Trata-se de uma preocupação partilhada por diferentes autores (BORREGO; KNIGHT; GIBBS JR; CREDE, 2018. WILCKIV; LYNCH; KAUFFMANN, 2014. ZOGHI, 2015). 
Em contrapartida, considerando-se a abrangência da formação em Engenharia de Produção, deve-se destacar que os profissionais com essa formação estão habilitados a atuar exercendo atividades em diversas áreas: de logística a finanças, perpassando disciplinas como ergonomia e qualidade, por exemplo. A formação em Engenharia de Produção se dá mediante abordagens teóricas e práticas. Especificamente no que se refere à prática profissional a formação de Engenheiros de Produção no Brasil requer que os estudantes realizem estágios supervisionados, ocasião em que têm a oportunidade de aplicar conhecimentos acadêmicos no universo empresarial.

O estágio na condição de atividade formativa pode se fazer acompanhar de uma remuneração (bolsa) concedida aos estudantes como forma de apoio, recompensa e estímulo financeiro pelo desempenho das atividades nas empresas. A remuneração dos estudantes pode variar de acordo com fatores organizacionais, mercadológicos e legais. Além disso, deve-se considerar que a remuneração auferida por estagiários pode variar em função da área de atuação, fato que pode eventualmente motivar os estudantes a optarem por áreas que sejam financeiramente mais atrativas.

É nesse contexto que o objetivo deste trabalho é apresentar uma análise da remuneração auferida por estudantes de Engenharia de Produção da Universidade Federal do Paraná que realizaram estágio na área financeira de 2017 a 2019. A análise se caracteriza como estudo de caso quantitativo que recorre à estatística descritiva para identificar eventuais fatores que possam estimular ou desestimular os estudantes a atuarem na área financeira. Para tanto, o artigo está estruturado em quatro seções além desta introdução. A seção 2 conta com uma breve revisão de literatura acerca da regulamentação da realização de estágios no Brasil. A seção 3 expõe os materiais e métodos do trabalho. A seção 4 apresenta e discute os resultados obtidos, cabendo à seção 5 as considerações finais do artigo.

\section{O estágio na formação em Engenharia de Produção}

O estágio profissional como atividade formativa essencial nos cursos de Engenharia é abordado por D'Agostino e Pinheiro (2003), autores que destacam a relevância de tal atividade como exercício da prática profissional em engenharia. A contribuição do estágio para o desenvolvimento de competências específicas para a formação em Engenharia de Produção é discutida por Ferreira e Reis (2016) com ênfase no papel do supervisor na formação profissional de estudantes de Engenharia de Produção. 
Francisco e Santos (2005) analisam especificamente os fatores críticos de sucesso para a aquisição de competências no estágio curricular supervisionado realizado por estudantes de engenharia do então chamado CEFET no Paraná. Os autores identificaram à época que deficiências na orientação e na utilização dos documentos gerados durante a realização do estágio são exemplos de importantes fatores críticos.

A relevância do estágio para a formação profissional é tamanha que justifica a composição de um arcabouço legal específico para regulamentá-lo. É nesse contexto que Marran e Lima (2011) promovem reflexões sobre o estágio curricular supervisionado no ensino superior brasileiro à luz da chamada "nova lei do estágio" (Lei 11.788/2008). Colombo e Ballão (2014), bem como Andrade e Resende (2015), nesse mesmo sentido, promovem justamente uma análise dos marcos regulatórios do estágio no Brasil, adotando para isso métodos documentais e bibliográficos de pesquisa. As autoras argumentam que ao longo das últimas décadas a legislação brasileira tem apresentado avanços ao considerar a dimensão prática das disciplinas curriculares.

Para efeito de contexto, o quadro 1 apresenta exemplos de leis referentes ao estágio no Brasil.

Quadro 1 - Legislação sobre estágios no Brasil

\begin{tabular}{|l|l|}
\hline \multicolumn{1}{|c|}{ Lei } & \multicolumn{1}{|c|}{ Objeto } \\
\hline Lei Federal 11.788/08 & $\begin{array}{l}\text { Dispõe sobre os estágios de estudantes no país, e sobre as } \\
\text { responsabilidades das partes envolvidas. }\end{array}$ \\
\hline Lei Federal 9.394/96 & $\begin{array}{l}\text { Dispõe que os sistemas de ensino estabelecerão as normas para a } \\
\text { realização dos estágios dos alunos regularmente matriculados. }\end{array}$ \\
\hline Lei Federal 6.494/77 & $\begin{array}{l}\text { Dispõe sobre os estágios de estudantes de estabelecimentos de ensino } \\
\text { superior e de ensino profissionalizante de segundo grau e supletivo. }\end{array}$ \\
\hline
\end{tabular}

Fonte: Elaborado a partir das leis citadas (2020)

O artigo $1^{\circ}$ da Lei 11.788 de 2008 define o estágio como:

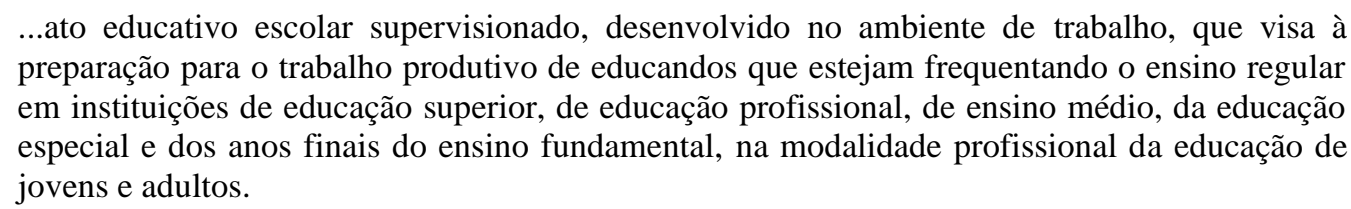

No que se refere à remuneração auferida pelo estudante em estágio, o artigo 12 da Lei 11.788 determina que "o estagiário poderá receber bolsa ou outra forma de contraprestação que venha 
a ser acordada, sendo compulsória a sua concessão, bem como a do auxílio-transporte, na hipótese de estágio não obrigatório".

No caso dos cursos de graduação em Engenharia que operam no Brasil, o artigo 7 da Resolução CNE/CES 11, de 11 de março de 2002 determina que:

\begin{abstract}
A formação do engenheiro incluirá, como etapa integrante da graduação, estágios curriculares obrigatórios sob supervisão direta da instituição de ensino, através de relatórios técnicos e acompanhamento individualizado durante o período de realização da atividade. A carga horária mínima do estágio curricular deverá atingir 160 (cento e sessenta) horas.
\end{abstract}

Em termos de procedimentos e regulamentações institucionais específicas, cada instituição de ensino superior brasileira pode contar com normativas e instâncias próprias. Na Universidade Federal do Paraná, instituição à qual estão (ou estavam) vinculados os estudantes cuja remuneração de estágio é analisada neste trabalho, a Resolução n. 46/10-CEPE é que dispõe sobre os estágios. Em termos de arranjo institucional, tem-se que:

\begin{abstract}
A Unidade de Estágios da Coordenação de Atividades Formativas e Estágios (UE/COAFE) da PROGRAD [Pró-Reitoria de Graduação] é a unidade administrativa responsável por gerenciar todos os estágios de estudantes da UFPR, bem como prestar auxílio pedagógico às coordenações dos cursos de graduação nos processos e nas políticas de estágio estabelecidas pelas resoluções do Conselho de Ensino, Pesquisa e Extensão (CEPE), em cumprimento à Lei Federal no 11.788/08. (COAFE, 2020)
\end{abstract}

No que se refere à remuneração, a UFPR esclarece que:

Estágios OBRIGATÓRIOS geralmente não são remunerados, e no caso de estágios obrigatórios realizados em órgãos públicos federais, estaduais e municipais, o pagamento de Bolsa Auxílio é explicitamente proibido (Orientação Normativa 02/2016 - MPOG; Decreto 8.654/2010 - Governo do Estado do Paraná; Instrução Normativa 3/2013 - IMAP Curitiba). (COAFE, 2020)

No que se refere aos auxílios financeiros de transporte, a UFPR informa que:

\begin{abstract}
A unidade concedente deve fornecer auxílio transporte diário para estagiários contratados na modalidade NÃO OBRIGATÓRIO. O valor do auxílio fica a critério da empresa contratante, e deve constar no Termo de Compromisso de Estágio (TCE). Estágios OBRIGATÓRIOS não asseguram o direito aos estagiários de receberem auxílio transporte. (COAFE, 2020)
\end{abstract}

À luz do exposto, este trabalho se pautou pela realização de uma análise comparativa da remuneração auferida por estagiários de Engenharia de Produção da UFPR, seguindo-se os procedimentos metodológicos descritos na seção seguinte.

\title{
3. Metodologia
}


Este trabalho se caracteriza como estudo de caso quantitativo respaldado por análises qualitativas. Os dados analisados neste estudo foram obtidos a partir de pesquisa documental: foram lidos 145 contratos de estágio no período de agosto a dezembro.Parte (42\%) dos contratos estava no formato online e $58 \%$ no formato físico. Os dados foram coletados ao longo do segundo semestre de 2019.

Os dados obtidos foram organizados em planilha eletrônica, sendo agrupadas em colunas com as seguintes informações:

a) Nome do(a) estudante;

b) Empresa contratante;

c) Cidade de realização do estágio;

d) Período cursado pelo(a) estudante;

e) Tipo de Estágio (obrigatório ou não obrigatório);

f) Aditivo;

g) Data de início do estágio;

h) Data de término do estágio;

i) Atividades realizadas pelo(a) estudante;

j) Valor da Bolsa;

k) Valor do auxílio transporte;

1) Carga Horária Semanal;

m) Professor(a) Orientador(a);

n) Nome do(a) Gestor(a);

o) Formação do(a) Gestor(a); e

p) Telefone do(a) Gestor(a).

Para o presente trabalho foram utilizadas as informações referentes aos valores da bolsa (o valor do auxílio transporte não foi adicionado ao valor da bolsa dos estudantes), a carga horária semanal e as atividades realizadas. As atividades serviram para classificar os estágios em termos de áreas de atuação, sendo elas:

a) Setor administrativo; 
b) Setor financeiro;

c) Setor comercial; e

d) Setor operacional.

Parte dos contratos apresentava a remuneração dos estudantes expressa em valores mensais, parte em valores por hora. Para viabilizar as análises, os dados expressos em hora foram convertidos em mensais (mediante multiplicação da carga horária semanal e então também por 4,5; que representaria a quantidade de semanas no mês) e os dados mensais também foram convertidos em remuneração por hora (mediante divisão do valor mensal pela carga horária semanal, sendo esta multiplicada novamente por 4,5 semanas). Com isso as análises apresentadas a seguir permitem a comparação das bolsas em termos mensais e em termos de valor por hora.

\section{Resultados}

A partir da análise dos dados obtidos nos contratos de estágio do tipo obrigatório e não obrigatório dos estudantes de Engenharia de Produção da UFPR, foi possível constatar que o setor operacional apresentou a maior quantidade de contratos, correspondendo a $43 \%$ de todos os contratos analisados no período de 2017 a 2019. O setor administrativo foi o segundo maior, com $21 \%$ do total de contratos, sendo seguido pelo financeiro (19\%) e administrativo (17\%), conforme representado no gráfico 1. Note-se que o resultado é esperado, considerando-se a natureza da formação dos estudantes (em se tratando de Engenharia de Produção), assim é plausível que os estudantes atuem em áreas operacionais das empresas contratantes. Além disso, a base de formação com disciplinas voltadas à gestão também os habilita à atuação em áreas administrativas e financeiras (atividades que, somadas, respondem por 36\% dos contratos de estágio do curso de Engenharia de Produção da UFPR). 
Gráfico 1 - Distribuição dos contratos de estágio por área de atuação dos estudantes de Engeharia de Produção da UFPR

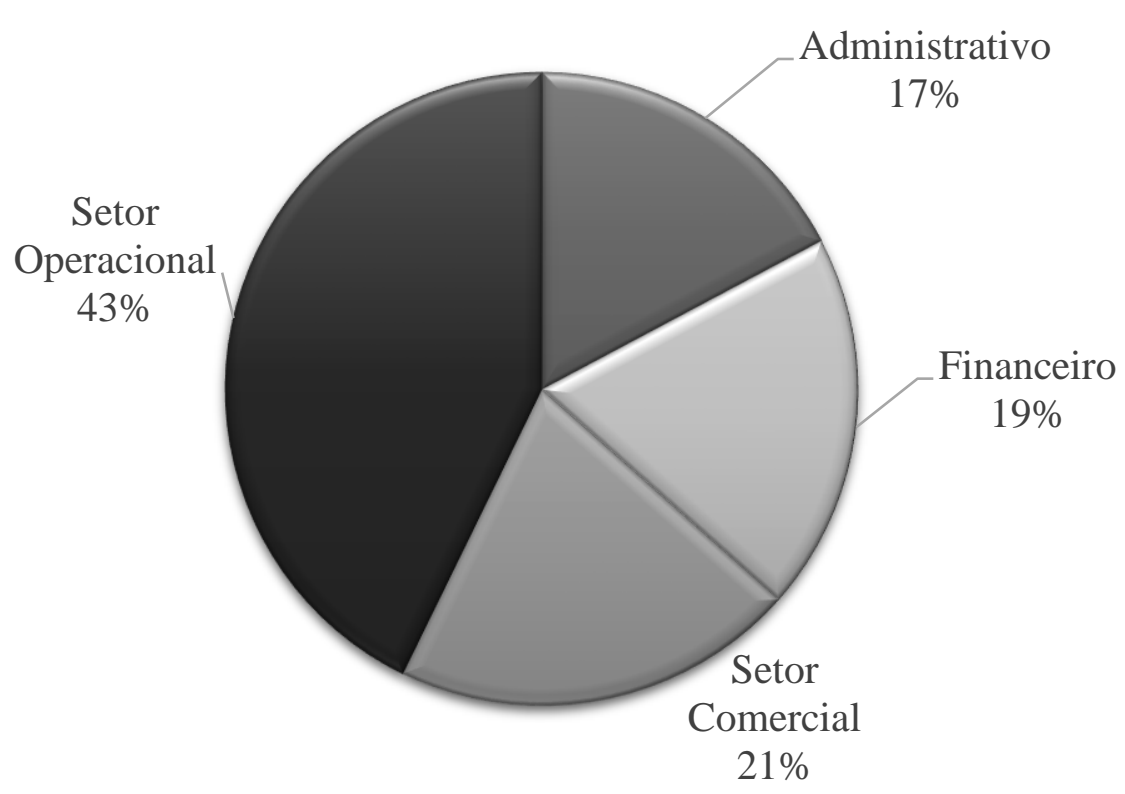

Fonte: Elaborado pelos autores a partir dos dados coletados (2020)

Em termos de remuneração, o setor financeiro (ainda que seja o segundo com menos contratos de estágio) é o que possui a maior média de bolsa-auxílio entre as quatro áreas, com uma média de R 12,29/hora. Contudo é também nesse setor em que há a maior variação na remuneração, com um desvio padrão de $\mathrm{R} \$ 4,40 /$ hora e valores que vão de $\mathrm{R} \$ 6,53 /$ hora a $\mathrm{R} \$ 20,62 /$ hora, conforme observa-se na tabela 1 . A título de comparação, cabe notar que o valor médio recebido por hora no caso de estudantes que estagiaram na área financeira foi aproximadamente $15 \%$ superior ao valor médio pago pelo setor operacional e $44 \%$ superior ao valor pago pelo setor comercial. O setor administrativo, por sua vez, foi o que apresentou a segunda maior remuneração por hora, com valor médio de $\mathrm{R} \$ 11,07 /$ hora (11\% inferior ao pago pelo financeiro, em média).

Cabe esclarecer que foi identificado um único caso de contrato com valor zero ( $\mathrm{R} \$ 0,00)$ referente à bolsa-auxílio, sendo este caso identificado para o setor operacional. Este caso foi suprimido da comparação por ser considerado outlier capaz de viesar as estatísticas. 
Tabela 1 - Estatísticas descritivas referentes à remuneração dos estagiários em Engenharia de Produção da UFPR (2017-2019), em valores por hora

\begin{tabular}{lccccc}
\hline & Administrativo & Financeiro & $\begin{array}{c}\text { Setor } \\
\text { Comercial }\end{array}$ & $\begin{array}{c}\text { Setor } \\
\text { Operacional }\end{array}$ & Total \\
\hline Contratos & 25 & 28 & 30 & 62 & 145 \\
Média & $\mathrm{R} \$ 11,07$ & $\mathrm{R} \$ 12,29$ & $\mathrm{R} \$ 8,54$ & $\mathrm{R} \$ 10,69$ & $\mathrm{R} \$ 10,62$ \\
Moda & $\mathrm{R} \$ 16,67$ & $\mathrm{R} \$ 7,51$ & $\mathrm{R} \$ 8,01$ & $\mathrm{R} \$ 16,67$ & $\mathrm{R} \$ 11,11$ \\
Mediana & $\mathrm{R} \$ 10,74$ & $\mathrm{R} \$ 10,74$ & $\mathrm{R} \$ 8,13$ & $\mathrm{R} \$ 9,81$ & $\mathrm{R} \$ 9,81$ \\
Desvio Padrão & $\mathrm{R} \$ 3,24$ & $\mathrm{R} \$ 4,40$ & $\mathrm{R} \$ 1,81$ & $\mathrm{R} \$ 3,70$ & $\mathrm{R} \$ 3,65$ \\
Variância & $\mathrm{R} \$ 10,52$ & $\mathrm{R} \$ 19,36$ & $\mathrm{R} \$ 3,27$ & $\mathrm{R} \$ 13,73$ & $\mathrm{R} \$ 13,34$ \\
Mínimo & $\mathrm{R} \$ 3,85$ & $\mathrm{R} \$ 6,53$ & $\mathrm{R} \$ 4,82$ & $\mathrm{R} \$ 5,19$ & $\mathrm{R} \$ 3,85$ \\
Máximo & $\mathrm{R} \$ 17,59$ & $\mathrm{R} \$ 20,62$ & $\mathrm{R} \$ 13,33$ & $\mathrm{R} \$ 21,48$ & $\mathrm{R} \$ 21,48$ \\
\hline
\end{tabular}

Fonte: Elaborado pelos autores a partir dos dados coletados (2020)

A bolsa-auxílio mais frequente observada nos contratos de estagiários que atuam na área financeira é a de $\mathrm{R} \$ 7,51 /$ hora e com uma mediana de $\mathrm{R} \$ 10,74 /$ hora. Quando comparados os valores da moda entre as áreas, o setor financeiro foi o que apresentou o menor valor, enquanto o setor administrativo e o operacional apresentaram os maiores ( $\mathrm{R} \$ 16,67 /$ hora para ambos). A mediana foi igualmente de $\mathrm{R} \$ 10,74 /$ hora para os setores administrativo e financeiro, ambos superiores às medianas do setor comercial ( $\mathrm{R} \$ 8,13 /$ hora $)$ e operacional $(\mathrm{R} \$$ 9,81/hora). O menor desvio padrão identificado foi de R\$1,81/hora para o setor comercial, sendo ele, conforme mencionado anteriormente, o que apresentou a menor remuneração média por hora $(\mathrm{R} \$ 8,54)$.

O maior valor pago por hora foi de $\mathrm{R} \$ 21,48$ em estágio realizado na área operacional, e o segundo foi de $\mathrm{R} \$ 20,62$, na área financeira. Se comparados os valores mínimos pagos por hora, o setor financeiro merece destaque por superar os demais $(\mathrm{R} \$ 6,53$, valor $26 \%$ superior ao menor valor pago pelo setor operacional, $\mathrm{R} \$ 5,19)$.

Quando considerados os valores mensais das bolsas auferidas pelos estagiários de Engenharia de Produção da UFPR, pôde-se identificar novamente que a média de remuneração da área financeira foi superior às demais, novamente com o maior desvio padrão, conforme expresso na tabela 2. 
Tabela 2 - Estatísticas descritivas referentes à remuneração dos estagiários em Engenharia de Produção da UFPR (2017-2019), em valores mensais

\begin{tabular}{lccccc}
\hline & Administrativo & Financeiro & $\begin{array}{c}\text { Setor } \\
\text { Comercial }\end{array}$ & $\begin{array}{c}\text { Setor } \\
\text { Operacional }\end{array}$ & Total \\
\hline Contratos & 25 & 28 & 30 & 62 & 145 \\
Média & $\mathrm{R} \$ 1.348,82$ & $\mathrm{R} \$ 1.607,41$ & $\mathrm{R} \$ 1.133,27$ & $\mathrm{R} \$ 1.370,16$ & $\mathrm{R} \$ 1.363,28$ \\
Moda & $\mathrm{R} \$ 1.500,00$ & $\mathrm{R} \$ 1.500,00$ & $\mathrm{R} \$ 1.081,00$ & $\mathrm{R} \$ 1.500,00$ & $\mathrm{R} \$ 1.500,00$ \\
Mediana & $\mathrm{R} \$ 1.352,95$ & $\mathrm{R} \$ 1.400,00$ & $\mathrm{R} \$ 1.081,00$ & $\mathrm{R} \$ 1.312,50$ & $\mathrm{R} \$ 1.300,00$ \\
Desvio Padrão & $\mathrm{R} \$ 340,92$ & $\mathrm{R} \$ 577,33$ & $\mathrm{R} \$ 256,65$ & $\mathrm{R} \$ 457,16$ & $\mathrm{R} \$ 454,24$ \\
Variância & $\mathrm{R} \$ 116.223,94$ & $\mathrm{R} \$ 333.306,81$ & $\mathrm{R} \$ 65.868,82$ & $\mathrm{R} \$ 208.992,81$ & $\mathrm{R} \$ 206.330,37$ \\
Mínimo & $\mathrm{R} \$ 520,00$ & $\mathrm{R} \$ 881,00$ & $\mathrm{R} \$ 651,00$ & $\mathrm{R} \$ 700,00$ & $\mathrm{R} \$ 520,00$ \\
Máximo & $\mathrm{R} \$ 2.114,10$ & $\mathrm{R} \$ 2.784,00$ & $\mathrm{R} \$ 1.800,00$ & $\mathrm{R} \$ 2.900,00$ & $\mathrm{R} \$ 2.900,00$ \\
\hline
\end{tabular}

Fonte: Elaborado pelos autores a partir dos dados coletados (2020)

A bolsa-auxílio mais frequente (moda) observada nos contratos de estagiários que atuam na área financeira é de $\mathrm{R} \$ 1500,00 /$ mês e com uma mediana de $\mathrm{R} \$ 1400,00 /$ mês. A moda do valor mensal pago pelo setor financeiro aos estagiários de Engenharia de Produção da UFPR igualou-se à do pago pelo setor administrativo e do setor operacional, superando em quase $40 \%$ a moda do setor comercial.

O menor valor mensal recebido entre 2017 e 2019 foi de $R \$ 520,00$, sendo verificado para o setor administrativo. O mínimo mensal pago pelo setor financeiro foi de $\mathrm{R} \$ 881,00$, maior dentre todos os setores comparados, superando em $26 \%$ o mínimo pago pelo setor operacional e em $69 \%$ o mínimo pago pelo setor administrativo. Por outro lado, o setor operacional foi responsável pelo maior valor mensal dentre todos: $\mathrm{R} \$ 2.900,00$, valor $4 \%$ superior ao máximo verificado para o setor financeiro. Por fim, cabe mencionar que o setor comercial foi o que pagou o menor valor máximo dentre todos $(\mathrm{R} \$ 1.800,00)$, sendo $62 \%$ do valor máximo praticado pelo setor operacional e $64 \%$ do valor máximo pago pelo setor financeiro.

As diferenças de remuneração entre as áreas parecem ser estatisticamente relevantes quando se considera o texto HSU assumindo-se o pressuposto de que remunerações maiores são melhores. Os resultados do teste HSU (intervalo de confiança de 95\%) constam na tabela 3. 
Tabela 3 - Resultados do teste HSU supondo “maior é melhor” para a remuneração dosestagiários de Engenharia de Produção da UFPR entre 2017 e 2019.

\begin{tabular}{lccc}
\hline \multicolumn{1}{c}{ Nível } & Média & $\begin{array}{c}\text { Limite } \\
\text { Inferior }\end{array}$ & Limite Superior \\
\hline Administrativo & $-258,592$ & $-513,142$ & 0 \\
Financeiro & 237,255 & $-3,271$ & 477,782 \\
Setor Comercial & $-474,145$ & $-706,517$ & 0 \\
Setor Operacional & $-237,255$ & $-398,895$ & 0 \\
\hline
\end{tabular}

Fonte: Elaborado via ActionStat utilizando os dados da pesquisa (2020)

O gráfico 2 contém a representação dos resultados do teste HSU, indicando haver diferença relevante no que se refere à remuneração dos estudantes

Gráfico 2 - Representação gráfica do teste HSU “maior é melhor” para a remuneração ds estagiários de Engenharia de Produção da UFPR entre 2017 e 2019

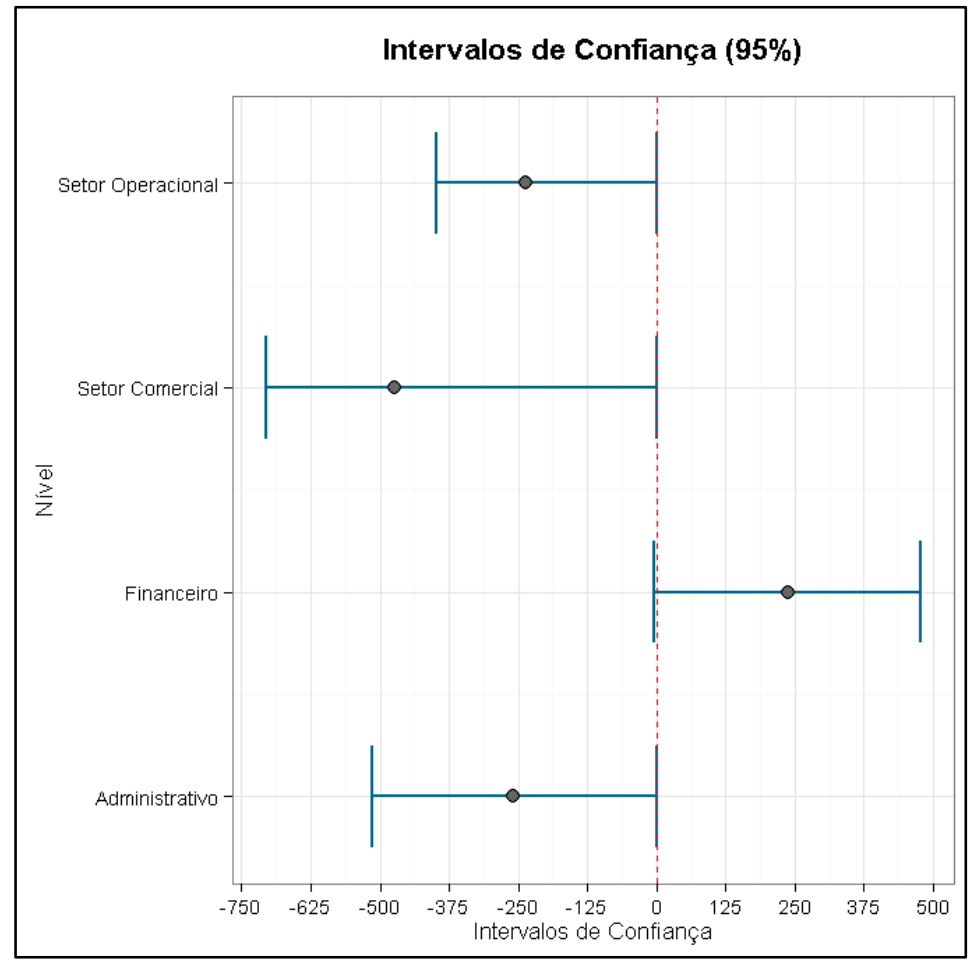

Fonte: Elaborado via ActionStat utilizando os dados da pesquisa (2020) 
Em termos gerais, tem-se, assim, indícios de que a remuneração auferida pelos estudantes que estagiaram na área de finanças foi relativamente maior do que as remunerações auferidas em outras áreas.

\section{Considerações finais}

Pautado pelo reconhecimento da importância do estágio supervisionado para a formação de profissionais de Engenharia de Produção, este trabalho teve como objetivo apresentar os resultados de um levantamento sobre o perfil da remuneração de estagiários da Universidade Federal do Paraná no período de 2017 a 2019. Sob uma perspectiva quantitativa, o trabalho delimitou-se à análise de contratos de estágio de estudantes que atuaram na área financeira de diferentes empresas. A partir da análise pôde-se identificar que:

a) O setor financeiro é o que possui a maior média na remuneração, com uma bolsa-auxílio mensal média de $\mathrm{R} \$ 1607,41$.

b) O setor financeiro é o que apresenta a maior variação na bolsa-auxílio, com um desvio padrão de R $\$ 577,33 /$ mês.

c) A bolsa-auxílio mais frequente de estagiários na área financeira é a de $R \$ 1500,00 / m e ̂ s$, igualando-se à do setor administrativo e do setor operacional.

O trabalho também constatou que a maioria dos contratos de estágio no período analisado eram voltados para atividades no setor operacional das empresas $(48 \%)$, enquanto o setor administrativo foi o que apresento uma menor quantidade de contratos, ainda que tenham sido $17 \%$ do total. Trata-se de um resultado convergente com a escolha do curso de graduação dos estudantes: em se tratando de Engenharia de Produção, é natural que a opção predominante sejam as áreas operacionais das empresas. Ademais, a bagagem gerencial que conquistam em sua formação também habilita os estudantes a atuarem em áreas financeiras, comerciais e administrativas.

Cabe notar que os resultados aqui obtidos indicam que pode haver certo estímulo financeiro para a atuação dos estudantes na área financeira: tanto a média quanto o piso mensal pago para estágios na área financeira superam os valores das demais áreas comparadas. Contudo, deve-se ressaltar que as escolhas de estágio realizadas pelos estudantes não são pautadas exclusivamente pela motivação financeira. A afinidade com a área, o horário de início e término do estágio, o tempo de deslocamento, o perfil da empresa, a disponibilidade total de 
vagas de estágio e o período cursado pelo estudante são exemplos de variáveis relevantes no processo de tomada de decisão que não podem ser negligenciadas. Nesse sentido, o trabalho se restringiu à análise comparativa das remunerações, cabendo abordar o peso e o papel das variáveis relevantes.

\section{REFERENCIAS}

ABEPRO - Associação Brasileira de Engenharia de Produção. Engenharia de Produção: grande área e diretrizes curriculares. Disponível em:

<http://www.abepro.org.br/arquivos/websites/1/Ref_curriculares_ABEPRO.pdf> Acesso em: 5 fev. 2020

AGOSTINO, Giuseppe D'; PINHEIRO, Antonio Carlos da Fonseca Bragança. O ESTÁGIO PROFISSIONAL COMO ATIVIDADE FORMATIVA NOS CURSOS DE ENGENHARIA. COBENGE 2003, São Paulo, p. 1-8, 2003. Disponível em: http://www.abenge.org.br/cobenge/arquivos/16/artigos/ECS536.pdf. Acesso em: 15 out. 2019.

ANDRADE, Rosana Cássia Rodrigues; RESENDE, Marilene. Aspectos legais do estágio: uma retrospectiva histórica. Revista Multitexto, [S.1.], v. 3, n. 1, p. 58-64, jun. 2015. ISSN 2316-4484. Disponível em: <http://www.ead.unimontes.br/multitexto/index.php/rmcead/article/view/108>. Acesso em: 05 fev. 2020.

BORREGO, Maura; KNIGHT, David B.;GIBBS JR, Kenneth; CREDE, Erin. Pursuinggraduatestudy: factorsunderlyingundergraduateengineeringstudents' decisions. JournalofEngineeringEducation, v. 107, n. 1, p. 140-163, 2018.

BRASIL. Lei $\mathbf{n}^{\mathbf{0}}$ 11.788, de 25 de setembro de 2008. Dispõe sobre o estágio de estudantes; altera a redação do art. 428 da Consolidação das Leis do Trabalho - CLT, aprovada pelo Decreto-Lei no 5.452, de 1o de maio de 1943, e a Lei no 9.394, de 20 de dezembro de 1996; revoga as Leis nos 6.494, de 7 de dezembro de 1977, e 8.859, de 23 de março de 1994, o parágrafo único do art. 82 da Lei no 9.394, de 20 de dezembro de 1996, e o art. 6o da Medida Provisória no 2.164-41, de 24 de agosto de 2001; e dá outras providências. [S. l.], 25 set. 2008. Disponível em: http://www.planalto.gov.br/ccivil_03/_ato2007-2010/2008/lei/111788.htm. Acesso em: 26 set. 2019.

BRASIL. Lei $\mathbf{n}^{0}$ 5.914, de 24 de dezembro de 1966. Regula o exercício das profissões de Engenheiro, Arquiteto e Engenheiro-Agrônomo, e dá outras providências. [S. l.], 20 abr. 1967. Disponível em: http://www.planalto.gov.br/ccivil_03/leis/15194.htm. Acesso em: 6 set. 2019.

COLOMBO, Irineu Mario; BALLÃO, Carmen Mazepa. Histórico e aplicação da legislação de estágio no Brasil. Educar em Revista, Curitiba, n. 53, p. 171-186, 2014. Disponível em: http://www.scielo.br/pdf/er/n53/11.pdf. Acesso em: 25 nov. 2019.

CONSELHO DE ENSINO, PESQUISA E EXTENSÃO. Sala das sessões, em 6 de agosto de 2010. RESOLUÇÃ̃ No 46/10-CEPE: Dispõe sobre os estágios na Universidade Federal do Paraná., [S. l.]: UFPR, p. 1-7, 6 ago. 2010. Disponível em: http://www.cppd.ufpr.br/portal/wpcontent/uploads/2019/08/resolucao_46_10_cepe_disposicao_sobre_os_estagios.pdf. Acesso em: 11 out. 2019.

CONSELHO NACIONAL DE EDUCAÇÃO CÂMARA DE EDUCAÇÃO SUPERIOR. 11 de março de 2002. RESOLUÇÃO CNE/CES 11, DE 11 DE MARÇO DE 2002. (*): Institui Diretrizes Curriculares Nacionais do Curso de Graduação em Engenharia., [S. l.], p. 1-4, 11 mar. 2002. Disponível em: http://www.abepro.org.br/arquivos/websites/1/Res_CNE_11-03-2002.doc. Acesso em: 17 out. 2019. 
content/uploads/sites/4/2019/01/Manual-de-Est\%C3\%A1gios-Vers\%C3\%A3o-Final.pdf. Acesso em: 30 out. 2019.

DE FRANCISCO, Antônio Carlos; DOS SANTOS, Neri. FATORES CRÍTICOS DE SUCESSO NA AQUISIÇÃO DE COMPETÊNCIA NO ESTÁGIO CURRICULAR SUPERVISIONADO: O CASO DOS CURSOS DE ENGENHARIA DO CEFET-PR. Revista Gestão Industrial, Curitiba, ano 2005, v. 01, n. 01, p. 26-36, 25 fev. 2005. Disponível em:

https://edisciplinas.usp.br/pluginfile.php/615807/course/section/204522/54704b310cf216f8cfa9ed06.pdf. Acesso em: 20 set. 2019.

FARR, John. V.; MERINO, Donald. N., SCHAEFER, Charles, V.; Educating entry-level engineers: are broadbased business/managerial skills a key to sustaining the US innovation-based economy? International Journal of Engineering Education, v. 19, n. 2, p. 252-259, 2003.

FERREIRA, Márcia Neves; REIS, Augusto da Cunha. Estágio Curricular Supervisionado: o Papel do Supervisor na Formação Profissional do Discente de Engenharia de Produção. Scientia Plena, Rio Janeiro, v. 12, n. 02, p. 1-9, 7 jan. 2016. Disponível em: https://www.scientiaplena.org.br/sp/article/view/2852. Acesso em: 2 dez. 2019.

MARRAN, Ana Lúcia; LIMA, Paulo Gomes. ESTÁGIO CURRICULAR SUPERVISIONADO NO ENSINO SUPERIOR BRASILEIRO: ALGUMAS REFLEXÕES. Revista e-curriculum, [s. l.], ano 2011, v. 7, n. 2, p. 119, 28 jun. 2011. Disponível em: http://revistas.pucsp.br/index.php/curriculum. Acesso em: 15 nov. 2019.

MEC - Ministério da Educação. Conselho Nacional de Educação. Diretrizes Curriculares Nacionais do Curso de Graduação em Engenharia. Disponível em: <http://portal.mec.gov.br/docman/marco-2019-pdf/109871pces001-19-1/file>. Acesso em: 5 fev. 2020.

WILCKIV, Joseph; LYNCH, Paul C.; KAUFFMANN, Paul J. Engineeringeconomics as a general educationcoursetoexpandquantitativeand financial literacy. ASEEAnnualConferenceand Exposition, ConferenceProceedings. 2014. Disponível em: http://www.scopus.com/inward/record.url?eid=2-s2.084905165197\& partnerID=tZOtx3y1 Acesso em: 06 fev. 2020.

ZOGHI, Shervin. Engineering Economics and its role in the engineering curricula. American Society for EngineeringEducationPaper, 2015. Disponível em:

<https://pdfs.semanticscholar.org/9f80/90aeb79f411b75a34354f37d6e4797e60cfa.pdf?_ga=2.64678124.210323 3079.1581000934-42924372.1562152529> Acesso em: 06 fev. 2020. 